\author{
¿Cómo citar este artículo? \\ García-Marín, E. y Garcés Giraldo, L. F. (septiembre-diciembre, 2018). La construcción del hogar \\ desde la ecología mental: entre la memoria y la creación del tejido social en Pueblo Bello. \\ Revista Virtual Universidad Católica del Norte, (55), 210 - 220.
}

\title{
| La construcción del hogar desde la ecología mental: entre la memoria y la creación del tejido social en Pueblo Bello ${ }^{1}$
}

The construction of the home from the mental ecology: the memory and the creation of the social fabric in Pueblo Bello

\section{María Eulalia García Marín}

Universidad Pontificia Bolivariana gemaldos@gmail.com

\section{Luis Fernando Garcés Giraldo}

Corporación Universitaria Adventista

lugarces70@gmail.com

Recibido: 11 de octubre de 2018

Evaluado: 09 de noviembre de 2018

Aprobado: 28 de noviembre de 2018

\section{| Resumen}

La ecología mental está en la memoria, es decir, el pasado de lo sucedido; las víctimas quieren saber ¿qué pasó?, ¿cómo pasó?, ¿đónde pasó?, ¿quiénes lo hicieron?, para lograr la construcción de la memoria y el tejido social en la comunidad de Pueblo Bello. Así las cosas, en este texto se propone la ecología mental como posibilidad de construir el oikos, el hogar, en sus dos manifestaciones: como lugar y como creación de relaciones, en aras de generar una nueva estética de la existencia, desde una experiencia común a la experiencia personal, a partir del tejido de varias puntadas. En esta investigación la metodología utilizada consta de dos partes, un rastreo detallado de referentes teóricos básicos, que fundamentan el texto, y la segunda, el trabajo de campo en distintos momentos cronológicos con la comunidad de Pueblo Bello.

Finalmente, se puede colegir que la construcción del oikos, como un nuevo tejido social, ayuda a sanar el dolor causado por la violencia y la crueldad, y se convierte en una práctica íntima, creando un lienzo, en el cual cada uno teje su corazón.

Palabras clave: Ecología mental, Ecosofía, Hogar, Memoria, Tejido social.

\section{| Abstract}

The mental ecology is in the memory, that is, the past of what happened, because people do not know it, how did it happen, where did it happen, who did it, to achieve the construction of memory and the social fabric in the community of Pueblo Bello. Therefore, in this text mental ecology is proposed as the possibility of building the home, the home, in its two manifestations: as a place and as a creation of relationships to generate a new aesthetics of existence, from a common experience to the personal experience from the knitting of several stitches. In this research the methodology became two parts, in the text and in the second, the fieldwork in the different chronological moments with the Pueblo Bello community. Finally, we can study the construction of tissues as a new social tissue helps to heal pain by violence, violence and behavior in intimate practice, the creation of a canvas, in the quality of each.

1 Artículo de reflexión derivado de la investigación doctoral "La construcción del OIKOS como estética de la existencia en Michel Serres: del espacio común a una experiencia personal". 
Keywords: Mental ecology, Ecosophy, Home, Memory, Social fabric.

\section{| Introducción}

"Yo no tengo ninguna casa ni a nadie en ningún sitio"

Halina Birenbaum (2015)

Para hablar de memoria y reconstrucción del tejido social, en comunidades atravesadas por múltiples formas de violencia y grados de crueldad, como es el caso de la comunidad de Pueblo Bello (Antioquia), se hace necesario preguntarse ¿cómo se reconstruye el hogar?

A lo largo de la historia del ser humano, este se ha visto abocado, de manera ineludible, a crear un lugar para vivir, para "resguardarse", el cual ha considerado su refugio, su abrigo, el espacio donde se ha sentido protegido, que ha estado oculto a las miradas del afuera, como lo plantea Michel Serres (1995): "el hombre no puede vivir sin refugio, es decir, públicamente, sin vida privada" (p. 53). Lugar considerado por muchos como algo sagrado, en tanto allí permanecen sus afectos, sus seres queridos y aquello considerado íntimo; ese oikos, manifestado como el hogar que, en el sentido de los griegos, era digno de ser abrigado. Dicho oikos ha sido modificado constantemente por múltiples manifestaciones de violencia, además por cambios climáticos y culturales que han llevado a transformaciones en los referentes mentales, según los momentos cronológicos y las características de las diferentes sociedades.

En este sentido, el texto propone el abordaje de la ecología mental como una posibilidad de construir el oikos, el hogar, en sus dos manifestaciones. Para ello, en la primera parte se menciona el por qué la ecología mental, entre la memoria y el tejido social, y se continúa con la propuesta acerca de la importancia de la ecología mental para construir tejidos sociales; finalmente, se presenta la reflexión sobre el concepto de ecosofía en Pueblo Bello (Antioquia).

\section{| Metodología}

Este texto es el resultado de una investigación en curso titulada: “La construcción del oikos como estética de la existencia en Michel Serres: del espacio común a una experiencia personal". El método de investigación ha sido el hermenéutico, porque ha permitido encontrar nuevos y diversos horizontes de comprensión, por medio del análisis de categorías importantes para el estudio del hogar, tales como: ecología mental, ecosofía, memoria y tejido social; además, su abordaje no solo se presenta desde el ámbito teórico, sino desde el práctico. Lo anterior, ha permitido establecer un diálogo prolífico con la tradición filosófica y con la propia perspectiva de interpretación, con el fin de obtener una visión de conjunto de la problemática.

De otro lado, se realizó la revisión de repertorios bibliográficos, en bases especializadas, para seleccionar las fuentes documentales pertinentes, con el fin de elegir la bibliografía primaria, secundaria y terciaria. Luego, se procedió con la clasificación de las fuentes documentales pertinentes, y con su lectura, análisis y sistematización.

Además de la construcción del inventario documental, se realizaron varias visitas al corregimiento de Pueblo Bello; alli se aplicaron entrevistas a los integrantes de la Casa Memoria: Remanso de Paz, así como a otros miembros de la comunidad, con el fin de identificar 
aspectos del tema sicosocial, que permitan, posteriormente, aplicar entrevistas estructuradas.

Adicionalmente, con el fin de presentar avances, en la investigación en curso, se realizaron dos ponencias, en los Foros Ambientales EcoPaz, de marzo y abril del 2016, con los temas, en su orden: la deforestación y la agricultura orgánica.

Así mismo, en el mes de marzo de 2017 se realizaron talleres ambientales con los niños del Paraje "Los Enamorados"; y con población adulta, en temas concernientes a lo pastoral. También, se realizó el recorrido "De los 43", en aras de profundizar en uno de los momentos más difíciles por los que pasó la comunidad, buscando con ello obtener más información, la cual permitiera profundizar en el conocimiento del territorio y de la comunidad, con el fin de elegir los instrumentos adecuados para aplicar a la población.

Finalmente, durante el segundo semestre de este año 2018 no fue posible viajar al territorio por situaciones de orden público, conocidas a través de los diferentes medios de comunicación. Por este motivo la investigación sigue abierta y se espera finalizarla en el 2019.

\section{¿Por qué la ecología mental, entre la memoria y el tejido social?}

Para empezar, es importante una precisión en torno al concepto de ecología, en el sentido en que esta abarca todas las manifestaciones de la vida, a nivel individual y social; por eso, Guattari (1996) señala que,

(...) la esencia de ese arte de 'la eco' que subsume todas las maneras de domesticar los territorios existenciales, tanto si conciernen a intimas maneras del ser, el cuerpo, el entorno o a grandes conjuntos contextuales relativos a la etnia, la nación o incluso los derechos generales de la humanidad. (p. 52).

Es decir, desde la ecología, como el estudio de la casa, de la morada, de la residencia, se puede iniciar la construcción de las relaciones humanas, a todos los niveles del individuo y de la sociedad, porque desde la interioridad del ser humano se inicia el cambio de pensamiento, de sentir. Es decir, al desearse esta transformación que es lenta, paulatina, dolorosa, llena de conflictos internos, entre el deseo de seguir, de perdonar, y el deseo de recordar el dolor de lo vivido y odiar, se entra en los terrenos de la ecología mental, al proponer que es desde lo íntimo del individuo donde se realiza la transformación de todas las interacciones en las comunidades, porque se transforma el pensamiento y, por ende, el espíritu; logrando cambios en la sociedad, en la ecología mental y en le ecología ambiental, como parte de un todo.

Esta nueva mentalidad ayuda a la creación de hábitos de pensamiento, los cuales permiten una manera diferente de relacionarse con el otro, que rompe con la vivencia de una cultura de crueldad y violencia; en este sentido, una manera de hacerlo es volver a la memoria que se tiene de lo sucedido, de lo que se cuenta, incluso de lo que se calla y a veces no se quiere contar ni repetir al otro; es decir, ir al pasado, a lo acontecido -que tiene que ver con el futuro, con lo que se proyecta- para proponer e intentar crear juntos. En esta medida, es posible aproximarse al concepto de la ecosofía mental, de Félix Guattari (2015), para inventar e imaginar nuevas formas de vivir en comunidad. Cuando las circunstancias, a veces, ocasionan roces, debido a las singularidades, se hace necesario transcender los sentimientos que se viven, buscando otros nuevos. Esto se puede comprender mejor al considerar el asunto desde el 
punto de la vista de las pasiones. A este respecto, vale la pena señalar que,

(...) la pasión triste habita en nosotros como una sombra. Donde vayamos siempre nos encontramos con ella. La pregunta fundamental a este análisis sería: ¿cómo podemos servirnos de las pasiones tristes en pro de nuestra alegría y así respirar el aire de la libertad? (Agudelo, 2011, p. 36).

Asi las cosas, es posible responder que el intento por vivir en las pasiones alegres posibilita crear lazos con los otros y generar en las poblaciones el nicho de unas relaciones armónicas, las cuales den cuenta de una cultura de la humanidad; lo anterior, al integrar los tres registros propuestos por Guattari (2015), como son: una ecosofía ambiental, una ecosofía mental y una ecosofía social.

\section{Ecología mental: un camino de posibilidad al tejido social}

En esta perspectiva, se puede considerar la ecología mental el punto de partida para proponer una reflexión sobre las relaciones que se establecen con los demás, al insistir en la formación del carácter, a partir de hábitos en el día a día, los cuales impliquen prácticas que se traduzcan en la confianza hacia el otro, para lo que se hace necesario "la renuncia a la violencia" (Sofsky, 2006, p. 10). Esta ecología de la psique se plantea como una vía para intentar construir -en el caso de Pueblo Bello- desde el dolor, la desconfianza y, en algunas situaciones, la ausencia de perdón, una realidad diferente que responda a nuevos proyectos para todos.

El proceso de construcción exige a cada uno, desde su interioridad, una transformación de sus sentimientos tristes, de manera que se aliente a cambiar la experiencia dolorosa, por nuevas emociones, las cuales permitan construir y potenciar nuevos horizontes, partiendo de la renuncia de cada individuo -como apuesta ética- al resentimiento y al deseo de venganza; lo anterior, aunado al deseo de continuar, que tienen muchos de los habitantes de este territorio, les ha permitido intervenir los aspectos de la educación, la salud, la cultura, el arte, el deporte, y ello ha dado como resultado una comunidad que intenta sobreponerse a los recuerdos dolorosos del pasado y seguir viviendo.

Por todo lo anterior, es posible proponer que esta rama de la ecología puede relacionarse con la experiencia de los pobladores de Pueblo Bello, porque al retar su interioridad, al pretender una mentalidad de ecuanimidad -ya que las relaciones se han fragmentado- se hace necesaria una reinvención del vivir, del hacer, del morir, del concepto de familia, de amistad, del amor, incluso de la muerte. Por eso, dice el filósofo francés Michel Serres (1995): que "toda partida supone que los hilos o los lazos se rompen" (p. 170); en este orden de ideas, hay que volver a entrelazar los territorios habituales, a partir del recuerdo que cada habitante tiene de lo sucedido, y la manera como lo narra ayuda a construir el tejido de lo inseparable, de aquello que los une, porque la separación marcó un punto de quiebre en las relaciones, una ruptura que hay que superar, lo que demanda en cada habitante prácticas de fortaleza y de templanza, en tanto exige al espíritu el ejercicio de la espontaneidad, es decir, reafirmarse en seguir viviendo, en no rendirse. A propósito de lo anterior, en el filme Plan de escape (King, Canton, Emmett, Furla y Brenne, 2013), Ray Breslin, en diálogo con Emil Rottmayer, al encontrarse en una prisión de máxima seguridad, dice que "quitarle la vida a un hombre no es nada, quietarle el corazón lo es todo", ya que cuando el corazón se rinde, el espíritu se quiebra, la vida ya no 
habita al ser humano.

En este punto, es posible decir que la primera puntada del tejido es el regreso al lugar del que fueron obligados a salir los habitantes, porque fueron forzados a abandonar su hábitat, su morada, con todo lo que ello incluía; en palabras de uno de los habitantes de Pueblo bello, "los lazos inquebrantables que tenían se rompieron"2. Entonces, se hace necesario iniciar un proceso de acercamiento al hogar que se tuvo, para empezar a apropiarse de ese lugar tan querido del que se estuvo ausente por mucho tiempo, y que rememora los hechos que interrumpieron la armonía, la paz, la alegría, la tranquilidad. Es limpiar, construir el espacio, lo que será la casa; acompañando estas labores de sentimientos de esperanza, con la ilusión que permita, a quienes regresaron, un volver a empezar.

Una segunda puntada es volver a tejer esos lugares comunes, a partir del recuerdo de lo que pasó (la memoria de lo que pasó); así, los implicados narran los lugares en los que se encontraban el día del atroz acontecimiento, por dónde pasó o pasaron los otros, con quiénes se encontraron en su recorrido, ¿qué acontecimiento providencial llevó a que se salvara, a que no fuera llevado o traído de un lugar, subido o bajado de un camión, ajusticiado o no en ese momento? Pero, también se recuerda a quienes murieron de manera inesperada, injusta, con la imposibilidad de no poderse defender; además, se rememora la impotencia de quienes lo presenciaron y tampoco pudieron hacer nada por ellos mismos y por los otros.

Y parte de este tejido es volver al lugar, es reconocer que los otros se fueron, tal y como se evidencia en las expresiones tejidas, las cuales se encuentran expuestas en la Casa de la Memoria Remanso de paz en Pueblo Bello, y entre las que están los siguientes recuerdos: "hasta siempre", "estarás por siempre en nuestros corazones", "que Dios te tenga a su lado", "vivirás siempre en mi corazón", "aún duele tu ausencia", "que Dios perdone a tus agresores", "siempre estarás en mi corazón”. Palabras que denotan la aceptación de una realidad que no se puede cambiar, y que, al tiempo, dan cuenta de la ausencia, del extrañamiento de los seres queridos, de aquellos que ya no están, del intento por encontrarse con los lazos del pasado y que aluden a los nichos afectivos que se tejieron con los seres queridos ya fallecidos.

Así mismo, se encuentra en Remanso de Paz la memoria generalizada de lo que todos los habitantes tenían y perdieron, y que representan con una imagen y una expresión; por ejemplo: "teníamos lazos familiares inquebrantables"3; este tejido realizado por una de las personas que perdió a sus familiares, muestra la importancia de las relaciones construidas con seres queridos que ya no están; aquí, de nuevo se habla del oikos como la manifestación de las relaciones. "Los animales sufrieron el abandono" (caballo); "dejamos de hacer lo que hacíamos", situación representada en el arriero al lado de la mula; "abandonamos nuestro patrimonio" (las vacas). Se teje la imagen de la casa, rodeada de una cerca, con techo de paja, las flores a un lado, que habla por sí sola de un lugar donde había vida, armonía, refugio.

2 Esta expresión está escrita en uno de los tejidos que fueron elaborados por los habitantes de Pueblo Bello, los cuales vivieron un brutal periodo de violencia entre los años 1990 a 1994, y que pueden apreciarse en la Casa de la Memoria: Remanso de paz en Pueblo Bello.

3 Otra de las expresiones que se conservan en los tejidos de la Casa de la Memoria: Remanso de paz, en Pueblo Bello. 
Una tercera puntada podría ser el intento por confiar en el otro, en el aquel ser humano "que me ha hecho daño" y que podría repetirlo, aquel que hace tiempo no veo, que no conozco. Ese intentar confiar se parece al movimiento del lazo que envuelve y aproxima, porque lo que cada uno hace desde su libertad, influye en el otro, porque se establecen uniones entre los participantes y "el lazo corre de un lugar a otro, se vuelve rígido o flexible" (Serres, 1995, p. 175); lo anterior, permite ilustrar que así pueden crearse las relaciones humanas, en tanto se aproxima al otro para confiar en que, al convertirse en unidad común, es decir comunidad, se pueden construir proyectos, tejer sueños, alcanzar metas, o se puede tener cierta reserva con los otros.

Por eso, cada cuerda se junta para hacer un tejido, es decir, el resultado es el conjunto de las cuerdas que se unen; en este caso, las relaciones que se vuelven a construir entre seres humanos de Pueblo Bello, que estuvieron separados por un período de diez años; habitantes que fueron desplazados por la violencia de los años 90, y que regresaron a su corregimiento, en promedio, en el año 2000, intentando comenzar de nuevo.

Se presenta, entonces, la propuesta de la ecología mental, uno de los tres registros del concepto de ecosofía propuesto por el pensador francés Félix Guattari (2015), como una forma de construir el tejido social en la comunidad de la que habla este texto, que fue violentada por todos los actores de la sociedad. La ecología mental permite cambiar lo social y ambiental, a partir de la transformación de la psique del ser humano. Esta construcción se ha identificado en las mujeres de Pueblo Bello, municipio de Turbo, quienes han liderado diferentes procesos para transformar su dolor y el sufrimiento propio, y el de tantas personas que vivieron la violencia de los años 80 y 90 en este lugar. Ellas, al igual que en la actividad de tejer -definido como: "Componer, ordenar y colocar con método y disposición algo" (Diccionario de la Real Academia Española, 2014)- conversan e idean maneras desde las cuales podían proponer a la población posibilidades de construir opciones y formas de idear el mundo; esta podría considerarse la cuarta puntada, al permitir que el espíritu cree desde su espontaneidad, es decir, reafirmarse en la vida del espíritu, lo cual es posible representar en la siguiente afirmación de Hannah Arendt (2010): “lo único que todavía impide a los hombres convertirse en cadáveres vivientes es la diferenciación del individuo, su identidad única" (p. 608). Y esta fuerza se puede llamar una ecología de la mente, la cual tiene que ver con el interior, con los pensamientos, con los referentes y creencias, en cuanto a la creación de una conciencia que ayuda a pasar por el tamiz de la razón todos los aspectos de la vida, incluido el aspecto ecosófico, en tanto se integran los distintos aspectos que hacen parte del entorno.

Esto fue lo que hicieron los habitantes de Pueblo Bello con la creación de las cooperativas, fundaciones y corporaciones ambientales, surgidas desde el año 2005, entre las cuales están: la Cooperativa de Trabajo Asociado de Productores Agropecuarios: Integración, Solución y Vida -PROASIV., que asocia a los productores agropecuarios y que se inicia el 13 de julio del 2005. A ella pertenecen cultivadores de cacao, caucho, plátano, arroz y maderables. Sus miembros han recibido asistencia técnica de algunos municipios de Urabá y de las Naciones Unidas. De la misma manera, se propicia la construcción del tejido social cuando aparece Arrieros por la paz, el cual nace en septiembre de 2014; este, según su representante legal Yesenia Luna Oviedo, es "un programa social para trabajar con la comunidad rural, víctima del conflicto, en pro de la construcción de paz en el corregimiento Pueblo Bello" (Comunicación personal, 15 de mayo de 2016), inicialmente, con familias asociadas de la cooperativa PROASIV o beneficiadas con proyectos de la misma. 
Ante los resultados del programa, las necesidades de la comunidad y la aceptación que tuvo Arrieros por la paz, se decidió darle un marco legal y constituir la Fundación Arrieros por la Paz el 26 de octubre del 2015. Este programa ha adelantado, hasta hoy, las siguientes iniciativas: Campamento arrieros por la paz (diciembre 2014), con ayuda del Programa de las Naciones Unidas para el Desarrollo -PNUD-, PROASIV y la comunidad en general; la estrategia Preparémonos para la paz, con jornadas de capacitación con la Gobernación de Antioquia, PNUD y PROASIV. En el 2014 se realizó el campeonato de fútbol Arrieros por la paz; además, ese mismo año se llevó a cabo el encuentro nacional sobre la construcción de paz, en 100 municipios en simultáneo, con el Ministerio del Trabajo y la ONU; el tema fue la paz necesita una economía más solidaria.

Igualmente, se han realizado los Foros Ambientales Ecopaz, en 2015 y 2016 (fecha en la que participaron los docentes de la Universidad Pontificia Bolivariana, con ponencias y charlas a la comunidad, en los meses de abril y noviembre). Estos foros se organizaron con la ayuda de la ONU, de Corpourabá, del Ministerio de Agricultura y Desarrollo Rural y de toda la comunidad. También, se ha adelantado la reforestación de algunas zonas del territorio entre 2014 y 2016 , además de la limpieza del río Mulatos, en donde participan los niños, los jóvenes y otras personas de la población.

Adicionalmente, se crea la Corporación Ambiental de Pueblo Bello -CORAMPUBE-, la cual trabaja, en alianza con la Fundación Arrieros por la Paz, en todas las iniciativas del registro ambiental de la zona. Se han creado las jornadas de Recetas por la paz, en las que intervienen mujeres de las diferentes veredas del corregimiento de Pueblo Bello. A la par, aparecen otras instituciones para la recreación y el deporte, tales como ASOPRACOL, que propende por la práctica deportiva como un elemento integrador de la sociedad, y AVIPAZ (Asociación de Víctimas para la Paz de Pueblo Bello), la cual busca trabajar con las víctimas en procesos de construcción de un nuevo tejido social, en aras de crear una cultura de paz.

Las anteriores experiencias permiten mostrar de qué manera se busca integrar lo ambiental con los otros aspectos de la sociedad, al realizar campañas de reforestación con los niños, convites para limpiar el río Mulatos, los cultivos de la tierra, y los foros ambientales; lo anterior, se manifiesta en la exposición de los tejidos, de la sala de la memoria Remanso de Paz, al igual que en las expresiones artísticas y deportivas, las cuales buscan crear una propuesta de integración de la comunidad, desde los diferentes ámbitos de la vida.

Toda esta dinámica permite entretejer, en sociedades permeadas por experiencias de conflicto, sufrimiento y violencia, y que están desligadas de sus territorios físicos y sociales, un modelo de relaciones simbióticas, desde el mutualismo, el comensalismo, la reciprocidad y la cooperación, en aras de la creación de nuevos nichos afectivos en territorios en construcción - "para no heredar la venganza” (Serres, 2015, p. 92)-, y que permitan integrar la recuperación de la pareja, de la familia, y del propio cuerpo, incluso, con aquellos aspectos sociales, con el fin de proponer una sociedad modélica, como la de Pueblo Bello. Este persistir y reafirmarse en continuar haciendo, es posible llamarlo la quinta puntada, y se pudo evidenciar en la persistencia de las mujeres que habitan este territorio; ellas inspiran y mueven con su trabajo al resto de la comunidad; así resulta inspirador para la comunidad el esfuerzo de ellas por entregar los víveres, por preparar cientos de almuerzos para los encuentros del Foro Ambiental Ecopaz. Así mismo, la preparación de cada detalle, para recibir a los estudiantes de las veredas que asisten, entregar los refrigerios a quienes llegan, recibir a los invitados y organizar los 
puestos de artesanías, en donde se venden los productos elaborados con los residuos de plástico, de cartón, las canastas de los huevos, además de algunos elaborados con las materias primas de la región de Urabá.

Es en Pueblo Bello, donde confluye la integración de los registros mental, social y ambiental con los otros aspectos de la sociedad, lo que muestra que es posible trabajar juntos, a la vez que se realizan algunas prácticas de reconciliación, reafirmando la propuesta de una sociedad más tolerante e incluyente, la cual se organiza desde las distintas ramas de la ecología, para generar lazos de identidad desde la perspectiva de un territorio en construcción, "el cual se constituye desde dos aspectos: la construcción política que generalmente puede hacerse por decreto y la construcción social que se hace desde la sociedad" (Boisier, 2004, p. 32).

Lo anterior, requiere de un forjar constante que hace habitable el oikopoiós. Es ese espacio del hogar, como relaciones tejidas en el día a día, y del espacio como lugar que acoge, lo que da como resultado una ecosofía; es decir, aquel camino para realizar la sabiduría y armonía ecológicas, para construir una vida que permita la protección de todas sus manifestaciones, al integrar los diferentes aspectos de la cotidianidad. Se llega así a la ecosofía, a la que es posible proponer como la sexta puntada de este tejido social.

\section{¿Por qué hablar de ecosofía en Pueblo Bello?}

Se propone el concepto de ecosofía en Pueblo Bello, porque según Guattari (2015) éste parte de la integración de las tres ecologías, como registros que se vinculan, y al hacerlo puede lograrse cierta sabiduría para vivir en la tierra, lo que requiere "interpretar la naturaleza" para vivir en ella de una manera diferente. Es una filosofía de la vida, una filosofía práctica que impulsa a una nueva comprensión del mundo, y que, además, propone una visión de unidad "en la que la especie humana pertenece al mismo sistema", por eso "se comprende la interconexión de todas las cosas y los frágiles equilibrios que la sustentan" (Guattari, 2015 p. 16); en palabras del jefe Seattle (trad. en 2015): "Pues nosotros sabemos que la Tierra no pertenece a los hombres, sino que los hombres pertenecen a la Tierra" (p. 13).

Este pensamiento ecosófico requiere una conciencia ecológica, una nueva mente, una nueva sensibilidad; exige crear un nuevo paradigma para lograr formas diferentes de relacionarse con los semejantes, lo que se puede alcanzar con una formación ecológica. Porque, si no se construyen las condiciones ideales para habitar en el mundo, los seres humanos podrían vivir en condiciones de antihumanismo, al perpetuar cadenas de odio y violencia, las cuales destruyen no solo la infraestructura, la naturaleza, sino también los lazos afectivos entre los humanos, porque como señala Sofsky (2006): “El dolor no deja ninguna puerta abierta a la esperanza (...) apresa a la víctima con todas sus fuerzas" (p. 79).

En este contexto de ruptura de la humanidad, poner en práctica la ecosofía requiere priorizar valores, ordenar ideas; además, es necesario tener claro un propósito, cuidar la tierra y a los demás seres vivos, con una sensibilidad ante lo que rodea. Se puede llamar a este pensamiento una ética ecológica que invita a reflexionar sobre las acciones y las consecuencias de estas, a corto, mediano y largo plazo, para intentar transformar el entorno en un hábitat de belleza y armonía. 
Esto es lo que se esfuerzan por construir los habitantes del corregimiento de Pueblo Bello -haciendo referencia a lo que se denomina ecosofía-; y para ello, se requiere actuar con un propósito que oriente y que esté animado por un sentido, el cual surge de la reflexión sobre la responsabilidad en la interacción con la tierra y con los demás seres vivos; ejemplo de esta conciencia es el intento de los habitantes de Pueblo Bello por conciliar la ecología con la economía, ya que las actividades realizadas permiten generar ingresos a la comunidad, a la vez que se educa en una práctica del cuidado del entorno; por tanto, se trata de una ética ecológica, porque las decisiones tomadas redundan en propuestas que apoyan la vida en todas sus dimensiones.

Esta preocupación por la vida como algo sagrado, que demanda reverencia ante ella, se encuentra en una de las corrientes del pensamiento filosófico actual, en la que se pasa de la ecosofía a una propuesta ecofilosófica, en la cual el retorno a la sensibilidad frente a todo lo que existe en el planeta es fundamental para cuidar y preservar. La propuesta la define Skolimowski (como se citó en Guattari, 2015) de la siguiente manera; "expresión filosófica de la nueva unidad entre los humanos, el planeta y los demás seres vivos" (p. 16); ello, porque se necesita de una nueva manera de ver, sentir y pensar la naturaleza, porque el planeta es el hogar de los seres humanos, ellos son sus administradores, sus custodios, sus guardianes; construyen en ella, influyen en su esencia, porque la transforman: "si tocamos la red en un punto ese contacto reverbera en todo lo demás, puesto que todos los elementos están conectados" (Guattari, 2015, p. 40).

Por eso, como se viene hablando de tejido social, la ecofilosofía sería la séptima puntada de los habitantes de Pueblo Bello, porque propone un reto, en relación con la comprensión que se tiene del hogar de todos, lo que implica el respeto por la vida humana y por la de los otros seres vivos, además de un conocimiento de la naturaleza. Lo anterior, implica una mente participativa, una reverencia por la vida, que se concreta en la construcción de la ecoética, porque los hombres son guardianes del ecohábitat, no meros usuarios; esta propuesta surge de la esencia del pensamiento ecosófico, planteado actualmente. Se traduce, además, en un nuevo lenguaje: "paz" como deseo, como práctica, como resultado, que parece imposible, pero siguiendo las utopías, puede hacerse realidad.

Dado que muchas de las acciones actuales deterioran el planeta, es necesario el humanismo ecológico, en el que se da un retorno al pensamiento de unidad entre la filosofía del hombre y la filosofía de la naturaleza, las cuales resultan ser dos caras de la misma moneda (Skolimowski, 2017, p. 116). Así las cosas, se propone la convergencia del humanismo y la ecología para lograr la unidad entre el mundo natural y el mundo humano, abarcando el entorno, para lograr equilibrio ecológico y equilibrio humano. Se fusionan, porque el ser humano es parte de la naturaleza y, al tiempo, propone sostener, transformar, administrar, hacer, consumir con equilibrio. Se concibe el mundo como un santuario en donde hay hábitats que cuidar, proteger, preservar, en aras de seguir viviendo, lo que requiere coherencia entre el sistema de valores, que genere un código ético y las creencias, para lograr un planeta armonioso, en el cual cuidar el hábitat ecológico muestra una extensión de la sensibilidad humana.

Lo anterior, plantea un regreso al conocimiento ancestral de las comunidades indígenas, de los campesinos y de pueblos primitivos, lo que se traduce en un pensamiento que parece nuevo, pero que vuelve a los orígenes de la relación con la vida, con la tierra; considérese, por ejemplo, la siguiente cita: "la ecofilosofía es un saber para incorporar a nuestra vida, que va de 
la mano de la razón y de la vida y se abrazan" (Skolimowski, 2017, p. 56), que requiere de unos valores ecológicos para supervivir en el planeta, con el resto de los demás seres vivos, en donde se exprese la transcendencia, una filosofía de la esperanza, con las aspiraciones culturales, espirituales y transcendentales, de un hombre lleno de facultades sensibles, estéticas y morales.

Es sabiduría como posesión del conocimiento adecuado para cierto estado del mundo, para ciertas condiciones de la sociedad, en donde cada uno pueda construir su intimidad desde lo más sublime y distinguido, buscando su armonía interior, el equilibrio, la claridad de visión, para reflexionar sobre el lugar en el planeta, para cultivar el entorno y reconstruir el mundo exterior, construyendo utopías para llevarlas a la vida cotidiana, para preservar el hábitat natural. La ecofilosofía propone vivir en la coherencia de un sistema de valores y una propuesta de "humanismo ecológico el cual enfatiza en lo que va aunado a la ecología mental" (Skolimowski, 2017, p. 116), en la medida en que se encuentra en la población de Pueblo Bello el deseo que tiene de salir adelante, de integrarse en la comunidad para construir un territorio de paz. De esta manera, se vuelve al significado del tejido, al entrelazar las fibras, las cuerdas y los lazos, de tal manera que el entramado sirva para tejer redes de unión, de intercambio y de fortaleza, con los hilos delgados y frágiles del amor, la confianza, la solidaridad, los cuales se aúnan con fuerza al tejido social y humano.

\section{| Conclusiones}

La ecología mental está entre la memoria y el presente, para construir el futuro; es decir, se debe recordar lo sucedido, porque las víctimas quieren saber ¿qué pasó?, ¿cómo pasó?, ¿dónde pasó?, ¿quiénes lo hicieron?, y va a la construcción del tejido social, buscando que el porvenir de lo que se teje en el presente vaya entretejido, como lazos para crear nuevas puntadas.

En la vida en sociedad de la comunidad de Pueblo Bello, sigue faltando un final a la construcción del tejido social, al ser el tema de la reconciliación y el perdón un asunto individual e integral que se da desde la intimidad de cada ser. Así mismo, la construcción del oikos como un nuevo referente simbólico, en condiciones de adversidad, ayuda a sanar el dolor causado por la violencia y la crueldad, y se convierte en una nueva estética de la existencia que va de la experiencia personal a una experiencia común, creando un lienzo, en el cual cada uno teje el corazón, para restaurarlo con fuerza, cuando se ha llegado a la profundidad del sufrimiento, del que solo es posible salir con el esfuerzo supremo de la voluntad, para lograr la transformación interior y transcender la vida.

Finalmente, al construir el concepto de oikos como una parte del tejido social, también se logra construir el concepto de justicia, en tanto que la violencia vivida generó una ruptura con el lugar y las relaciones, de tal magnitud que se requiere volver al orden establecido, porque el hombre quiere su casa ordenada. 


\section{| Agradecimientos}

A la comunidad del corregimiento de Pueblo Bello, municipio de Turbo; a Yesenia Luna Oviedo, la representante legal de la Fundación Arrieros por la Paz; a Miriam Guarín, representante de la Corporación Ambiental de Pueblo Bello (Corampube); y a los integrantes de la Casa Memoria: Remanso de Paz.

\section{| Referencias}

Arendt. H. (2010). Los orígenes del totalitarismo. Madrid, España: Alianza Editorial.

Agudelo, L. (2011). Una hermenéutica de la libertad humana en la ética de Spinoza. Medellín, Colombia: Universidad Pontificia Bolivariana.

Birenbaum. H. (2015). La esperanza es la última en morir: un viaje al pasado. Auschwitz, Alemania: Museo Estatal de Auschwitz-Birkenau.

Boisier, S. (septiembre, 2004). Desarrollo territorial y descentralización. El desarrollo en el lugar y en las manos de la gente. Revista Eure, 30(90), 27-40.

Guattari, F. (1996). Las tres ecologías. (José Pérez y Umbelina Larraceleta, Trads.). Valencia, España: PRE-TEXTOS.

Guattari, F. (2015). ¿Qué es la ecosofía? (Pablo Ires, Trad.). Buenos Aires, Argentina: Cactus.

Jefe Seattle. (2015). Carta del indio Seattle. (Carmen Bravo-Villasante, Trad.). Barcelona, España: José J. de Olañeta.

King, K., Canton, M., Emmett, R., Furla, G. y Brenne, R. (Productores) y Håfström, M. (Director). (2013). Plan de escape. [Película]. Estados Unidos, Summit Entertainment.

Real Academia Española. (2014). Diccionario de la lengua española (23 ed.). Madrid, España: Real Academia Española. Recuperado de http://dle.rae.es/?id=ZKibnfG

Serres, M. (1995). Atlas. Madrid, España: Cátedra.

Serres, M. (2015). Figuras del pensamiento. Autobiografía de un zurdo cojo. Barcelona, España: Gedisa.

Skolimowski, H. (2017). La ecofilosofía como un árbol de vida. (Francisco López Martín, Trad.). Girona, España: Atalanta.

Sofsky, W. (2006). Tratado sobre la violencia. Madrid, España: Abada. 